\title{
Metallurgical effect on the mechanical behavior of rotary endodontic files using finite element analysis
}

\author{
Manar Galal(iD
}

\begin{abstract}
Background: The aim of this study was to evaluate the mechanical behavior of M-wire, controlled memory (CM), and R-phase files under bending and torsion conditions and compare it to the mechanical response of NiTi file with the same geometry using finite element analysis.

Methods: A geometric model of HyFlex file size 25 and taper 0.06 was generated by micro-computed tomographic and stereomicroscope scanning. The file FE model was built using MATLAB and SolidWorks software. Four FE files models were constructed with different material properties, the data for the M-wire, CM, R-phase, and NiTi alloys were obtained from the literature. The mechanical behavior of the different models under bending and torsion was analyzed mathematically in SolidWorks software package.

Results: Under bending conditions, the maximum Von Misses stress value was related to NiTi file model (330 MPa), followed by M-wire (311 MPa), then CM file model (191 MPa), while the least amount of stress value was related to R-phase file model (169 MPa). When torsion test was performed the maximum stress value was also related to NiTi file model (270 MPa), followed by M-wire (261 MPa), then CM file model (191 MPa), while the least amount of stress value was related to R-phase file model (188 MPa).
\end{abstract}

Conclusions: Metallurgical improvement of rotary files resulted in increasing the flexibility and the torsional resistance of these files.

Keywords: Bending, Torsion, Finite element analysis, CM-wire, R-phase, M-wire, NiTi

\section{Background}

In recent decades, nickel-titanium $(\mathrm{NiTi})$ rotary files have gained increasing popularity over stainless steel files in root canal preparation due to the superelastic behavior of nitinol-based materials. NiTi files present several advantages compared with stainless steel files, such as higher flexibility, fewer canal aberrations, and a shorter procedural duration. However, fracture of NiTi files remains a concern in clinical practice. An instrument might fracture at various levels of stress or strain, with or without any apparent signs of plastic deformation adjacent to the fracture site. This is due to the presence of residual stresses in the instrument after use. Two mechanisms of fracture have been proposed, torsional (shear) and flexural (fatigue).

Correspondence: manargalal@windowslive.com

Restorative and Dental Materials Department, National Research Centre, El-Bohouth Street, Dokki, PO Box 12311, Cairo, Egypt
There are several contributing factors that affect the fracture of rotary NiTi instruments (Saber 2008), and to improve the fracture resistance of $\mathrm{NiTi}$ rotary files, manufacturers have introduced new alloys with higher mechanical properties. Most rotary $\mathrm{NiTi}$ files are fabricated from near-equiatomic NiTi alloys, which contain approximately $55 \mathrm{wt} . \%$ nickel (Santos et al. 2013). Testarelli et al. (2011) compared the bending properties of the HyFlex instruments with other NiTi rotary instruments. The results revealed that the Hyflex instruments were the most flexible, but the comparisons were made among instruments with different geometric designs. Several studies of the stresses generated in NiTi instrument have been completed using finite-element (FE) analysis. FEA allows easy evaluation of the influence of various materials on the mechanical properties of the same geometric model. Thus, differences resulting from the geometry of 
the instruments are eliminated. The aim of the present study was to evaluate the mechanical behavior of M-wire, controlled memory (CM), and R-phase files under bending and torsion conditions and compare it to the mechanical response of NiTi file with the same geometry using finite element analysis.

\section{Materials and methods}

\section{Creation of a finite element model for NiTi files}

Real-size, a digitized model of HyFlex CM file (Coltene, Whaledent), size 25 and taper 0.06 , was obtained by micro-computed tomography scanning (GE Discovery VCT, Germany) to obtain a 3D geometric model. The file was imaged using a stereomicroscope (Technival 2, Carlzeiss JENA) at $\times 5, \times 10$, and $\times 16$ magnifications to obtain a detailed shape. To build the file's 3D model, the file cross section was drawn in 2D using computer-aided design programs CAD (SolidWorks software package). The 2D file with (.prt) extension was converted into stereolithographic (.stl) extension to be readable by programming software (MATLAB software). Building of 3D model in form of sections was performed by MATLAB software using the following data: taper of the file, change in pitch length, and cross section. After building of the 3D model on MATLAB, the file model was imported to computer-aided design programs CAD (SolidWorks software package). The file (.stl) extensions were converted to (.prt or .sldprt) to be edited by computer-aided design programs CAD (SolidWorks software package). Finishing of the file 3D model was performed by building the tip and the handle of the file using computer-aided design programs CAD (SolidWorks software package). Using computer-aided design programs CAD (SolidWorks software package) FE model for the file was done. The meshing of the model was done by (Cosmos, SolidWorks software package) using linear, six-node trihedral elements. The final FE model of the HyFlex instrument consisted of 5268 elements with 9206 nodes (Fig. 1).

\section{Mathematical analysis of FE models}

The mathematical analysis of files was performed on SolidWorks software package. The necessary parameters to describe each model were entered. For CM file, model data were extracted from the stress-strain relationships determined by Zhou et al. (2012) for the $48 \mathrm{CM}$-wire tested at room temperature. The material properties for M-wire file model are obtained from the stress-strain relationships found in the literature (Montalvão et al. 2014). The parameters used to describe the model of the R-phase file superelastic NiTi were derived from stress-strain curve determined by Santos et al. (2016). The nonlinear, stressstrain behavior of the NiTi material was entered for NiTi file model during the mathematical analysis. The Young's modulus of the alloy was $36 \mathrm{GPa}$, while the Poisson's ratio was 0.3 according to Wang (2007).

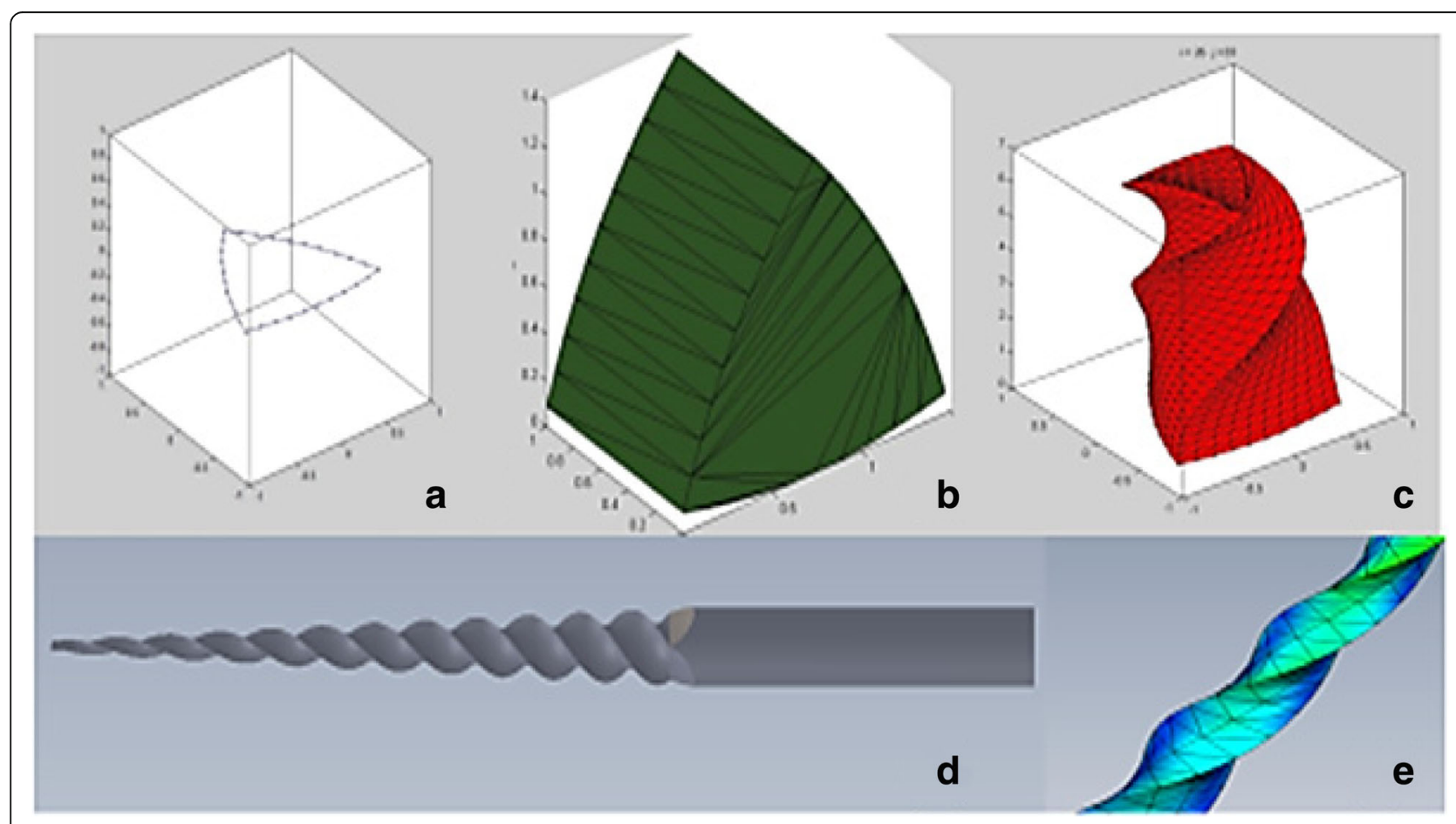

Fig. 1 a 2D drawing of HyFlex file cross section in SolidWorks software. b, c The building of the 3D model of HyFlex file in MATLAB software. $\mathbf{d}$ 3D models of HyFlex file. e Meshing of the FE models of HyFlex file 


\section{Bending}

Cantilever bending was simulated for the four FE models by applying a concentrated load of $1 \mathrm{~N}$ at the tip of the file with its shaft rigidly held in place (Kim et al. 2009). The vertical displacement was measured, and the von Mises stress distribution was evaluated.

\section{Torsion}

Application of a shear moment (torsion) 2.5 N.mm moment of force was applied to the shafts of the four models in a clockwise direction (Kim et al. 2009), while the last $4 \mathrm{~mm}$ of the tip was rigidly constrained. The stress distribution was evaluated.

\section{Results}

\section{Bending}

When bending test was performed, the maximum stress value was related to NiTi file model $333 \mathrm{MPa}$ with displacement $2.26 \mathrm{~mm}$, followed by M-wire file model 311 $\mathrm{MPa}$ and $2.44 \mathrm{~mm}$ displacement, then CM file model 191 $\mathrm{MPa}$ and $3.39 \mathrm{~mm}$ displacement. On the other hand, the least value of stress was related to R-phase file model 169 $\mathrm{MPa}$ with $9.75 \mathrm{~mm}$ displacement. Stress distribution showed that maximum stress value was related to the cutting edges of the apical $4 \mathrm{~mm}$ of all files (Fig. 2) (Table 1).

\section{Torsion}

When the torsion test was performed, the maximum stress value was related to NiTi file model $2.70 \mathrm{MPa}$ followed by $\mathrm{M}$-wire file model $2.61 \mathrm{MPa}$, then $\mathrm{CM}$ file model $1.91 \mathrm{MPa}$. The least stress value was related to Rphase file model $1.88 \mathrm{MPa}$. Stress distribution showed that the maximum von Mises stress of was situated at the base of the flutes just below the constrained $4 \mathrm{~mm}$ of apical end of the all tested files (Fig. 3) (Table 1).

\section{Discussion}

In the present study, finite element analysis (FEA) was used to compare the mechanical behavior of conventional NiTi, M-wire, CM, and R-phase files during bending and torsion. FEA is the method of choice for theoretical analysis of the mechanical behavior of NiTi files which subjected to complex loading forces. It offers the advantage that individual variables and combinations of variables can be tested systematically in a way that is not possible experimentally. The same geometric model was used for all types of files models to eliminate the influences of geometrical characteristics so the difference in the mechanical property of the models would be the result of the different metallurgy (Santos et al. 2016). NiTi alloy may present two main properties, SE (pseudoelasticity) and shape memory effect (SME). The SE is related to the presence of stable austenite that when the alloy is subjected to load, it gives rise to B19 stressinduced martensite. This phase is unstable at temperatures above Af and thus returns to austenite by a reverse transformation when the load is removed, and the strain is recovered (Santos et al. 2013). Therefore, the working temperature for conventional superelastic NiTi files must be above the Af (Otsuka and Wayman 1998;

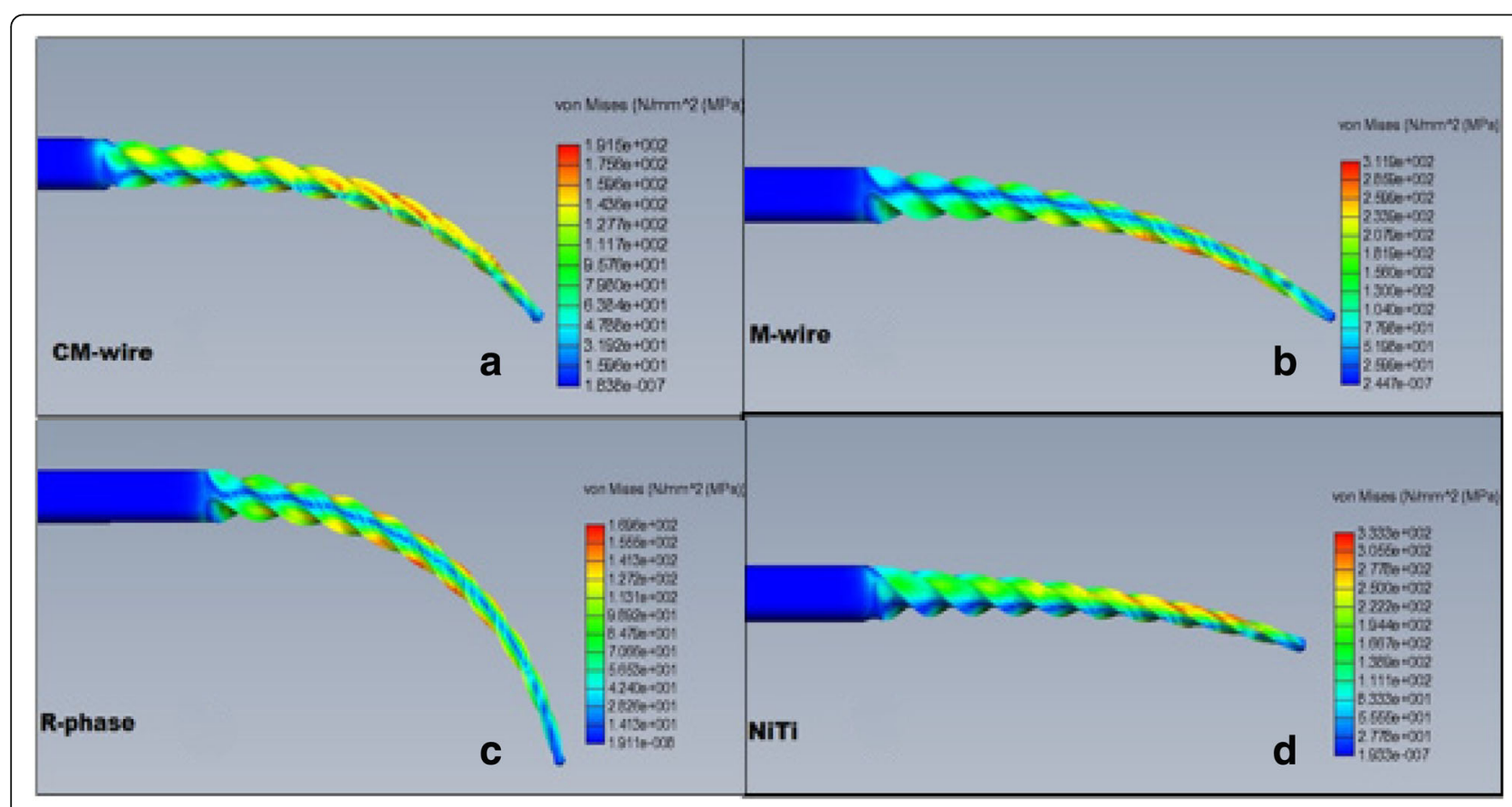

Fig. 2 a-d Stress distribution during bending of CM-wire, M-wire, R-phase, and NiTi FE models, respectively 
Table 1 Showing the maximum stresses value during bending and torsion and showing the maximum displacement during bending of files with different metallurgy

\begin{tabular}{llll}
\hline Alloy & Max. stress during bending $(\mathrm{MPa})$ & Max. displacement during bending $(\mathrm{mm})$ & Max. stress during torsion $(\mathrm{MPa})$ \\
\hline CM-wire & 191 & 3.39 & 1.91 \\
M-wire & 311 & 2.44 & 2.61 \\
R-phase & 169 & 9.75 & 1.88 \\
NiTl & 333 & 2.26 & 2.70 \\
\hline
\end{tabular}

Otsuka and Ren 2005). There is a third phase besides B19 martensite and austenite called R-phase, that is formed in some cases as an intermediate phase during transformations between austenite and martensite. The transformation temperatures affected by thermomechanical processing, and it is possible to obtain stable austenite, R-phase, martensite, or an alloy containing a mixture of these phases (M-wire) depending on the manufacturing process. R-phase is less stiff than the other two phases, thus allowing for stress relaxation during deformation of endodontic instruments inside root canals; this means that the loads needed to deform files, either in bending or in torsion is also much smaller. The mechanical properties of the NiTi alloy affected by the phases present; thus, thermomechanical treatments consider a modern technique of developing new endodontic instruments with improved mechanical properties (Santos et al. 2016).

When bending test was performed, NiTi file model showed the greatest flexural rigidity, and the lowest displacement; this was in full agreement with Montalvão et al. (2014). The lowest stress value and the maximum displacement was related to R-phase file model during the bending simulation, which indicates a superior flexibility of this alloy. This was in full agreement with Figueiredo et al. (2009) who concluded that martensite has a fatigue life 100 times greater than that of austenite. This behavior is related to the crack propagation mechanism in martensite, which occurs through the large number of branched cracks that formed along the numerous interfaces present in the martensitic phase. The crack propagation is very slow because of the dissipation of energy produced by the branching of the cracks. While, in the superelastic NiTi, the cracks form a limited number of branches which leads to decrease the energy consumption and the increase the crack (McKelvey and Ritchie 2001). Martensite is induced more easily in R-phase than in austenite, and it can be favorable for a greater fatigue life. R-phase has a much smaller stiffness than the other two phases, thus allowing for stress relaxation during deformation of endodontic instruments inside root canals; this means that the loads needed to deform files, either in bending or in torsion, are also much smaller. CM file model showed less Von Misses values than $\mathrm{M}$-wire and NiTi FE models did during bending. This was in full agreement with Santos et al. (2013) who reported that $\mathrm{CM}$ files do not present the rebound effect after unloading, and their original shape is restored after autoclaving. The behavior of these files due to the presence of stable martensite means that the working

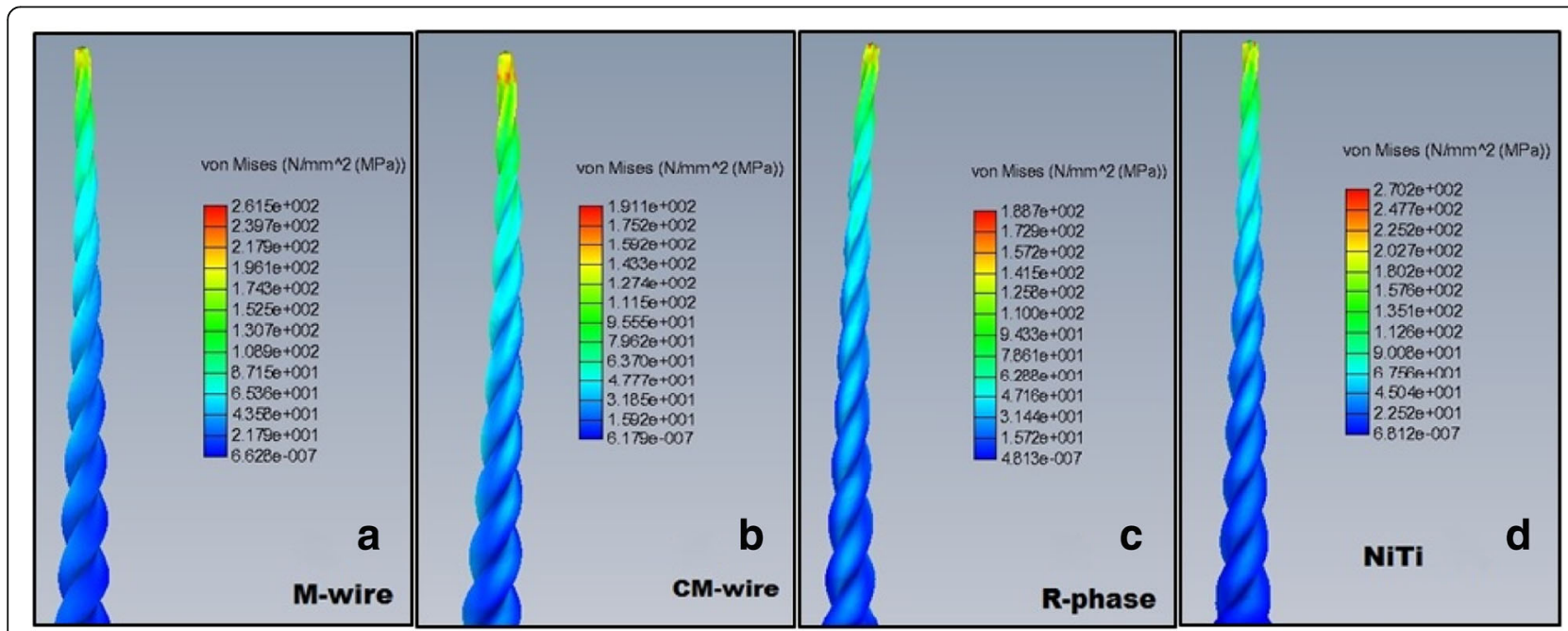

Fig. 3 a-d Stress distribution during torsion of CM-wire, M-wire, R-phase, and NiTi FE models, respectively 
temperature is below the Af. Stable martensite is known for the capacity to recover the original shape by reverse transformation after heating the deformed martensite to temperatures above the Af. These temperatures are related to the nickel content of the alloy and to the thermomechanical treatment for NiTi wire. M-wire FE model showed more stress values and less displacement than CM file model did; this was in full agreement with Pongione el al (2012) who compared the mechanical properties of $\mathrm{M}$-wire and CM alloys. On the other hand, the maximum Von Misses stress was related to NiTi FE model; this was in full agreement with Montalvao et al. (2014).

When bending test was performed, stress distribution was similar in the four models, and it was related to the cutting edges of the apical half of the files, so the core was preserved from the damaging effect of the stress concentration (Santos et al. 2013). This stress distribution was expected from the mechanics of bending a beam of triangular cross section; this was in full agreement with Kim et al. (2009) and Berutti et al (2003). When torsion test was performed again the least amount of Von Misses stress was related to R-phase FE model followed by CM model then M-wire FE model, while the maximum amount of Von Misses stress was related to NiTi FE models. The mechanical behavior of the files was related to the thermomechanical treatment effect on the alloy; this was in full agreement with Santos et al. (2013). Stress distribution was similar in the four file models, and it was related to the base of flute immediately below the constrained area; this was in full agreement with Kim et al. (2009).

\section{Conclusion}

Metallurgical improvement of rotary files resulted in increasing the flexibility and the torsional resistance of these files. The type of the alloy used in manufacturing of rotary files affects its mechanical properties. R-phase file model showed the highest flexibility and torsional resistance among the tested groups, while CM file model was more flexible and torsional resistance than $\mathrm{M}$-wire file model. The least flexibility and torsional resistance were related to NiTi file model.

\section{Acknowledgements}

Not applicable

Authors' contributions

MG is the contributing author for this research. The author read and

approved the final manuscript.

Funding

The author funds the financing cost of the research paper.
Ethics approval and consent to participate

Not applicable

Consent for publication

Not applicable

\section{Competing interests}

The author declares that she has no competing interests.

Received: 16 January 2019 Accepted: 17 July 2019

Published online: 01 August 2019

\section{References}

Berutti E, Chiandussi G, Gaviglio I, Ibba A (2003) Comparative analysis of torsional and bending stresses in two mathematical models of nickel-titanium rotary instruments: ProTaper versus ProFile. J Endod 29:15-19

Figueiredo AM, Modenesi P, Buono V (2009) Low-cycle fatigue life of superelastic NiTi wires. Int J Fatigue 31:751-758

Kim TO, Cheung GSP, Lee JM, Kim BM, Hur B, Kim HC (2009) Stress distribution of three NiTi rotary files under bending and torsional conditions using a mathematic analysis. Int Endod J 42:14-21

McKelvey AL, Ritchie RO (2001) Fatigue-crack growth behavior in the superelastic and shape-memory. Metall Mater Trans 32:731-743

Montalvão D, Shengwena Q, Freitaset M (2014) A study on the influence of Ni-Ti $M$-wire in the flexural fatigue life of endodontic rotary files by using finite element analysis. Mater Sci Eng 40:172-179

Otsuka K, Ren X (2005) Physical metallurgy of Ti-Ni-based shape memory alloys. Prog Mater Sci 50:511-678

Otsuka K, Wayman CM (1998) Shape memory materials, 1st edn. Cambridge University Press, Cambridge

Pongione G, Giansiracusa A, Lisotti F, Milana V, Testarelli L (2012) Mechanical properties of endodontic instruments made with different nickel titanium alloys: a stiffness test. ENDO (Lond Engl) 6:41-44

Saber $S$ (2008) Factors influencing the fracture of rotary nickel titanium instruments. ENDO (Lond Engel) 2:273-283Santos LA, Bahia MG, De Las Casas EB, Buono VT (2013) Comparison of the mechanical behavior between controlled memory and superelastic nickel-titanium files via finite element analysis. J Endod 39:1444-1447

Santos LA, Resende PD, Bahia MG, VTI B (2016) Effects of R-phase on mechanical responses of a nickel-titanium endodontic instrument: structural characterization and finite element analysis. Sci World J 2016:7617493. https://doi.org/10.1155/2016/7617493Testarelli L, Plotino G, Al-Sudani D (2011) Bending properties of a new nickeltitanium alloy with a lower percent by weight of nickel. J Endod 37:1293-1295

Wang GZ (2007) A finite element analysis of evolution of stress-strain and martensite transformation in front of a notch in shape memory alloy NiTi. Mater Sci Eng A 460:383-391

Zhou H, Shen Y, Zheng W (2012) Mechanical properties of controlled memory and superelastic nickel-titanium wires used in the manufacture of rotary endodontic instruments. J Endod 38:1535-1540

\section{Publisher's Note}

Springer Nature remains neutral with regard to jurisdictional claims in published maps and institutional affiliations. 